\title{
Efficient differentiation of human embryonic stem cells to arterial and venous endothelial cells under feeder- and serum- free conditions
}

\author{
Gopu Sriram ${ }^{1,2}$, Jia Yong Tan ${ }^{1}$, Intekhab Islam³ ${ }^{3}$ Abdul Jalil Rufaihah ${ }^{4,5}$ and Tong Cao ${ }^{1,6,7^{*}}$
}

\begin{abstract}
Background: Heterogeneity of endothelial cells (ECs) is a hallmark of the vascular system which may impact the development and management of vascular disorders. Despite the tremendous progress in differentiation of human embryonic stem cells (hESCs) towards endothelial lineage, differentiation into arterial and venous endothelial phenotypes remains elusive. Additionally, current differentiation strategies are hampered by inefficiency, lack of reproducibility, and use of animal-derived products.

Methods: To direct the differentiation of hESCs to endothelial subtypes, $\mathrm{H1}$ - and H9-hESCs were seeded on human plasma fibronectin and differentiated under chemically defined conditions by sequential modulation of glycogen synthase kinase-3 (GSK-3), basic fibroblast growth factor (bFGF), bone morphogenetic protein 4 (BMP4) and vascular endothelial growth factor (VEGF) signaling pathways for 5 days. Following the initial differentiation, the endothelial progenitor cells $\left(\mathrm{CD} 34^{+} \mathrm{CD} 31^{+}\right.$cells) were sorted and terminally differentiated under serum-free conditions to arterial and venous ECs. The transcriptome and secretome profiles of the two distinct populations of hESC-derived arterial and venous ECs were characterized. Furthermore, the safety and functionality of these cells upon in vivo transplantation were characterized.
\end{abstract}

Results: Sequential modulation of hESCs with GSK-3 inhibitor, bFGF, BMP4 and VEGF resulted in stages reminiscent of primitive streak, early mesoderm/lateral plate mesoderm, and endothelial progenitors under feeder- and serumfree conditions. Furthermore, these endothelial progenitors demonstrated differentiation potential to almost pure populations of arterial and venous endothelial phenotypes under serum-free conditions. Specifically, the endothelial progenitors differentiated to venous ECs in the absence of VEGF, and to arterial phenotype under low concentrations of VEGF. Additionally, these hESC-derived arterial and venous ECs showed distinct molecular and functional profiles in vitro. Furthermore, these hESC-derived arterial and venous ECs were nontumorigenic and were functional in terms of forming perfused microvascular channels upon subcutaneous implantation in the mouse.

Conclusions: We report a simple, rapid, and efficient protocol for directed differentiation of hESCs into endothelial progenitor cells capable of differentiation to arterial and venous ECs under feeder-free and serum-free conditions. This could offer a human platform to study arterial-venous specification for various applications related to drug discovery, disease modeling and regenerative medicine in the future.

Keywords: Human embryonic stem cells, Endothelial differentiation, Arterial, Venous, Serum-free, Feeder-free

\footnotetext{
*Correspondence: dencaot@nus.edu.sg; tong_cao@nuhs.edu.sg

${ }^{1}$ Oral Sciences Disciplines, Faculty of Dentistry, National University of

Singapore, Singapore 119083, Singapore

${ }^{6}$ NUS Graduate School for Integrative Science and Engineering, Singapore

117456, Singapore

Full list of author information is available at the end of the article
} 


\section{Background}

The vascular system consists of a complex network of arteries and veins that are lined by a monolayer of cells called endothelial cells (ECs). Although the arterial and venous ECs share certain common molecular signatures such as the expression of pan-endothelial markers (CD31, vascular endothelial cadherin (VE-CAD), and von Willebrand factor (vWF)), they do possess certain distinct molecular profiles $[1,2]$. Such molecular distinction seems to occur quite early in the development even before the onset of blood flow and involves the interplay of various signaling pathways such as sonic hedgehog (Shh), vascular endothelial growth factor (VEGF), Notch, cyclic adenosine monophosphate (cAMP), and chicken ovalbumin upstream promoter-transcription factor II (COUP-TFII) [3]. Arterial ECs are characterized by expression of Ephrin-B2, Delta-like 4 (DLL4), Hey-1, Hey-2, neuropilin-1 (NRP1), Notch-1, Notch-4, chemokine receptor-4 (CXCR4), Jag-1 and Jag-2, while the venous ECs express Eph-B4, Lefty-1, Lefty-2, neuropilin-2 (NRP2) and COUP-TFII [1]. Due to lack of access to human embryos, most of our understanding regarding the molecular mechanisms of arterial-venous specification is based on studies in zebrafish, Xenopus and mouse embryos, and a few studies using stem/progenitor cells. Additionally, genetic, molecular and functional studies of human ECs are limited by the availability of umbilical, neonatal or adult sources.

Recent advances in stem cell biology have provided a surrogate tool to study human development through pluripotent stem cells (PSCs) that include human embryonic stem cells (hESCs) and induced pluripotent stem cells (iPSCs) [4]. Differentiation of PSCs into ECs is of growing interest as it provides an opportunity to study vascular development in both physiological and diseased states. Secondly, the PSC-derived ECs could serve as a surrogate human vascular model to study various cellular and molecular aspects of angiogenesis [5]. Furthermore, these cells also provide access to abundant populations of cells for the pharmaceutical industry to screen and develop novel cardiovascular compounds [6,7]. Finally, in the long term, these cells have the potential for cellular therapy to repair ischemic tissues and develop tissueengineered vascular grafts.

We and others have reported differentiation of hPSCs towards mature and functional ECs [8-17]. Briefly, these protocols involve: (1) embryoid body-based differentiation, (2) co-culture of PSCs over murine stromal cells, and (3) monolayer differentiation over extracellular matrix (ECM) proteins like Matrigel and collagen IV $[5,18]$. Despite the tremendous progress in differentiation of hESCs towards endothelial lineage, very limited data are available on how these stem cells could be coaxed into arterial or venous ECs. Secondly, these differentiation protocols have limitations such as low differentiation efficiency and use of xenogeneic (animal-derived) products such as fetal bovine serum (FBS), murine feeder cells and/or ECM [5]. Additionally, the undefined nature of serum and other xenogeneic components limits the ability to tune the cellular microenvironment and in turn affects the efficiency and reproducibility of the protocol [16, 19]. Furthermore, these xenogeneic components limit the clinical translation potential owing to potential risk of transmission of animal pathogens, and ectopic expression of immunogenic minor histocompatibility antigens that could lead to xenogeneic rejection [16]. Hence, large-scale production of ECs from hESCs for various research and clinical applications would require: (1) efficient induction of hESCs towards endothelial lineage and specifically towards different arterial and venous ECs, and (2) elimination or reduction of xenogeneic products.

A reliable approach to generate ECs from hESCs would be to recapitulate the embryonic vasculogenesis under defined conditions based on a thorough understanding of the key developmental events and signaling pathways controlling them. In this study, we established a stepwise differentiation of hESCs to arterial and venous ECs through stages reminiscent of Brachyury ${ }^{+}$ primitive streak (PS), VEGFR2 ${ }^{+}$early mesoderm/lateral plate mesoderm, CD $34^{+} \mathrm{CD} 31^{+}\left(\mathrm{VEGFR} 2^{+}\right)$endothelial progenitors and then to arterial $\left(\mathrm{CD} 31^{+} / \mathrm{NRP}^{+} / \mathrm{DLL}^{+}\right)$ and venous $\left(\mathrm{CD} 31^{+} / \mathrm{NRP}^{+} / \mathrm{EphB} 4^{+}\right)$ECs under feederand serum-free conditions. These endothelial phenotypes displayed differences in transcriptome and secretome profiles, they were nontumorigenic and formed functional blood vessels that integrated with the host circulation and maintained their respective phenotypes in vivo.

\section{Methods \\ Culture of hESCs under feeder-free and serum-free conditions}

For feeder- and serum-free culture, H1- and H9-hESCs (WiCell Research Institute, Madison, WI, USA) were cultured in chemically defined medium $\left(\mathrm{mTeSR}^{\mathrm{Tm}} 1\right.$; StemCell Technologies) on Matrigel-coated plates (356230, BD Biosciences) as previously described [20]. Briefly, 70-80 \% confluent hESCs were passaged after treatment with $1 \mathrm{mg} / \mathrm{ml}$ dispase (Invitrogen) for $5 \mathrm{mi}$ nutes at $37{ }^{\circ} \mathrm{C}$. The hESC colonies were dispersed into small clumps and re-plated onto Matrigel-coated plates. The pluripotency status of the hESCs was confirmed by immunocytochemical expression of OCT4, SSEA3/4, TRA-1-60, TRA-1-81 and alkaline phosphatase (Additional file 1: Figure $\mathrm{S} 1$ ). 


\section{Directed differentiation of hESCs under chemically defined conditions}

After incubation with dispase ( $1 \mathrm{mg} / \mathrm{ml} ; 5$ minutes), undifferentiated hESC colonies of size $\sim 300-500$ cells per colony were gently cut into small squares using a $200 \mu \mathrm{l}$ gel loading pipette tip under a stereomicroscope (Olympus). These cut hESC colonies were gently aspirated and seeded onto $4 \mathrm{\mu g} / \mathrm{cm}^{2}$ human plasma fibronectin (GIBCO)-coated plates (seeding density: $\sim 2 \mathrm{hESC}$ colonies $/ \mathrm{cm}^{2}$ ). The pluripotency status of hESCs seeded onto fibronectin-coated plates for 24 hours was investigated by real-time reverse-transcriptase polymerase chain reaction (RT-PCR) and immunocytochemical staining (Additional file 1: Figure S2). These hESC colonies on fibronectin were maintained in $\mathrm{mTeSR}^{\mathrm{max}} 1$ for 24 hours, after which the cells were gently washed with DMEM:F12 (Invitrogen) and differentiated in chemically defined, serum-free, animal component-free medium [21] (STEMdiff APEL $^{\mathrm{mw}}$; StemCell Technologies) supplemented with appropriate factors as depicted in Figs. 1 and 2. To induce hESCs towards PS,

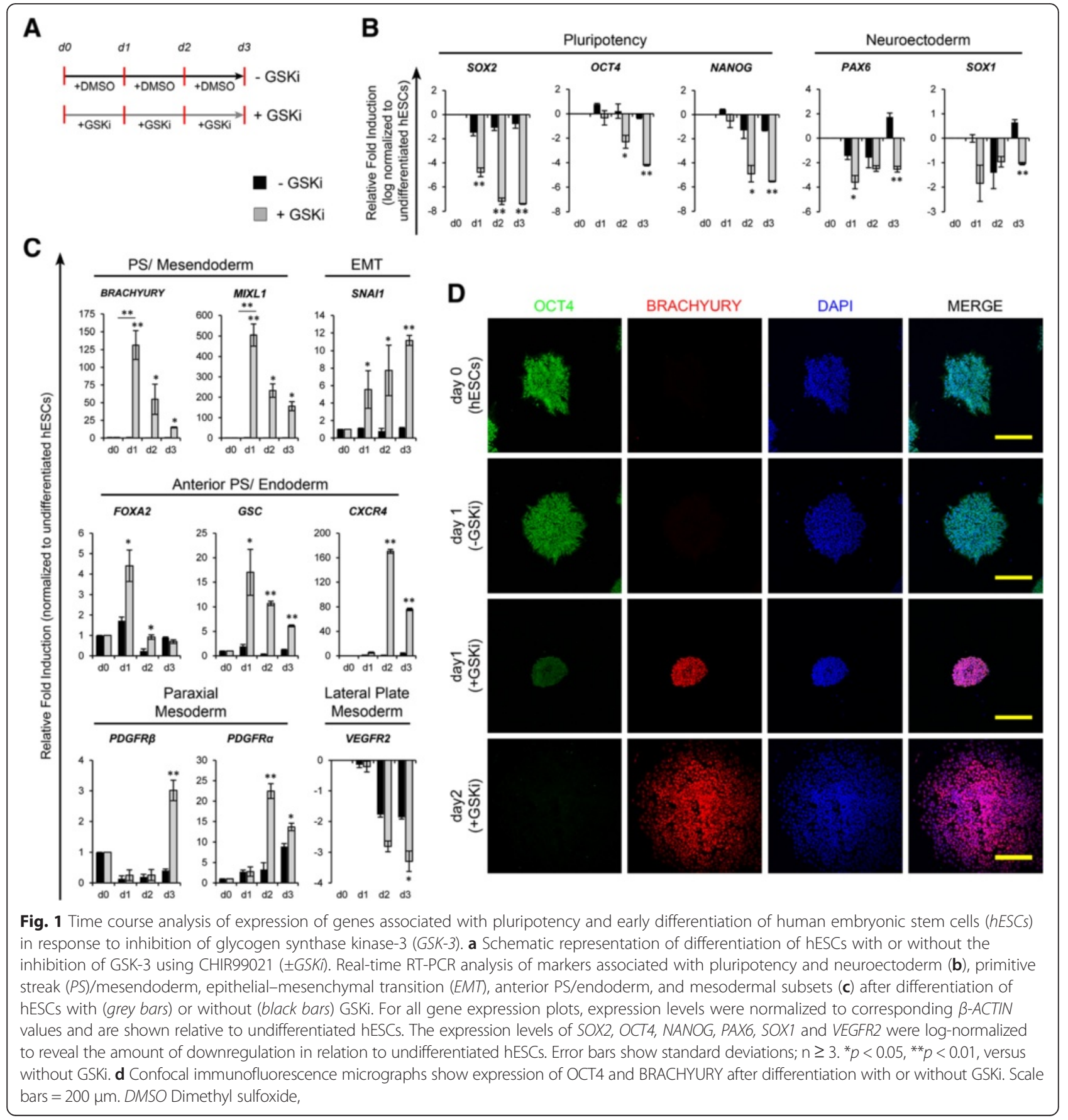




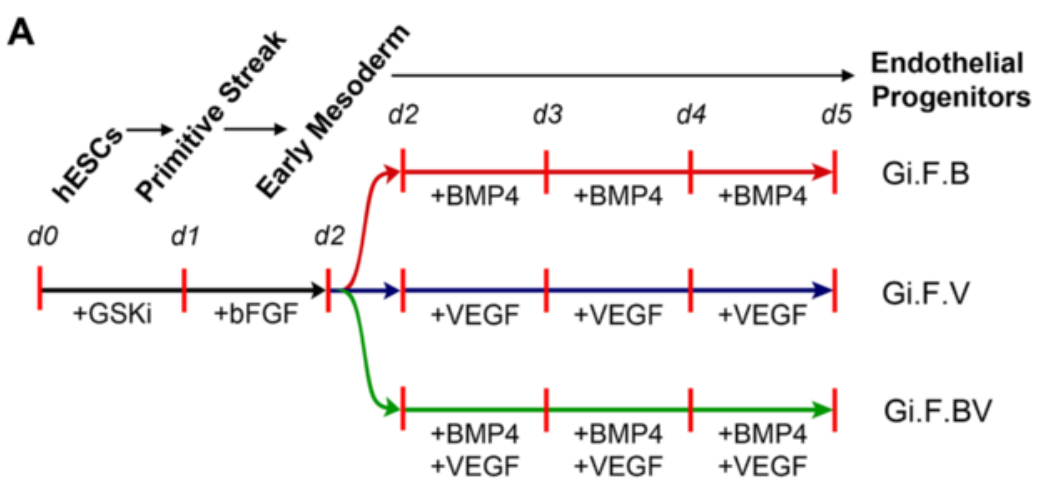

B
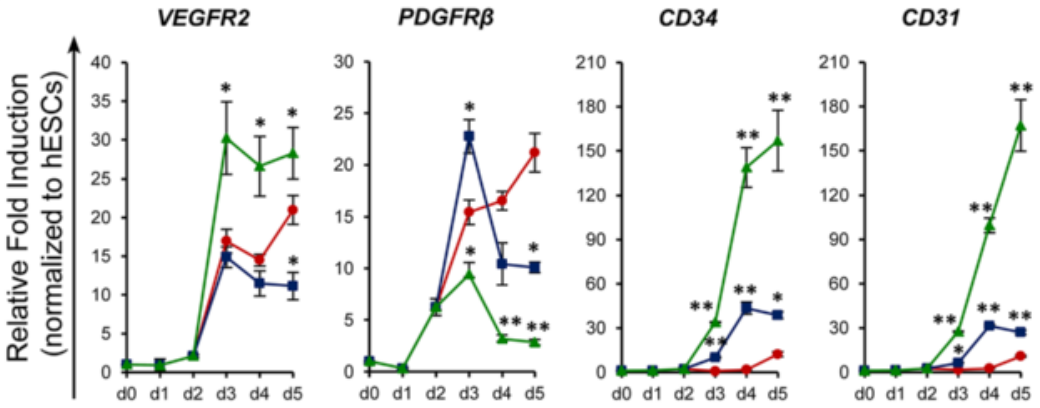

C
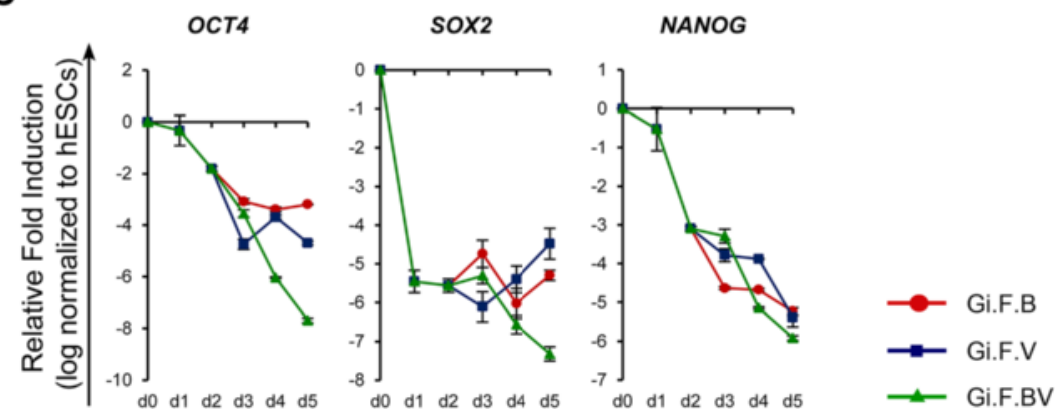

Fig. 2 Kinetics of transcripts associated with early endothelial induction and pluripotency of human embryonic stem cells (hESCS). a Schematic representation of differentiation of $\mathrm{H1}$-hESCs towards endothelial progenitors by sequential treatment with CHIR99021 (+GSKi) and basic fibroblast growth factor (bFGF) for 24 hours each followed by exposure to bone morphogenetic protein 4 (BMP4) and/or vascular endothelial growth factor (VEGF). b Kinetics of expression of VEGFR2, CD34 and CD31 upon induction with BMP4 (Gi.F.B), VEGF (Gi.F.V) and BMP4 + VEGF (Gi.F.BV) over a differentiation period of 5 days. c Time course expression kinetics of pluripotency genes (OCT4, SOX2, NANOG) over 5 days of differentiation among the three differentiation conditions. For gene expression plots in (b) expression levels were normalized to corresponding $\beta$-ACTIN values and are shown relative to undifferentiated hESCs, while for those in (c) the expression levels were log-normalized to reveal the amount of downregulation in relation to undifferentiated hESCs. Error bars show standard deviations; $\mathrm{n} \geq 3 .{ }^{*} p<0.05,{ }^{* *} p<0.01$, versus Gi.F.B

the hESCs were exposed to glycogen synthase kinase-3 (GSK-3) inhibitor (CHIR99021; $5 \mu \mathrm{M}$; Stemgent) for 24 hours as previously reported $[17,22]$. After 24 -hour exposure of hESCs to CHIR99021, mesodermal induction of PS was carried out using basic fibroblast growth factor (bFGF) $(50 \mathrm{ng} / \mathrm{ml})$ with or without FGF receptor inhibitor (PD173074; $0.1 \mu \mathrm{M}$ ), and endodermal differentiation of PS was induced using Activin-A (50 ng/ml) with or without Activin and transforming growth factor (TGF) $-\beta$ signaling inhibitor SB431542 $(10 \mu \mathrm{M})$ as illustrated in Additional file 1 (Figures S3 and S4). Following induction of PS, mesodermal and endothelial induction was carried out in the presence of bFGF (50 ng/ml; R\&D systems) for 24 hours followed by 72 hours of bone morphogenetic protein 4 (BMP4; $25 \mathrm{ng} / \mathrm{ml}$; R\&D systems) and VEGF (50 ng/ml; GIBCO) (Fig. 2a).

\section{Differentiation of endothelial progenitors $\left(\mathrm{CD} 34^{+} \mathrm{CD} 31^{+}\right.$} cells) to endothelial subtypes in feeder-free, serum-free conditions

After 5 days of differentiation in STEMdiff ${ }^{\mathrm{m}} \mathrm{APEL}^{\mathrm{Tm}}$, $\mathrm{CD} 34^{+} \mathrm{CD}_{31}{ }^{+}$cells were isolated by flow cytometry 
assisted sorting (FACS), and plated onto $2 \mu \mathrm{g} / \mathrm{cm}^{2} \mathrm{hu}$ man plasma fibronectin-coated plates $(12,000$ cells per $\mathrm{cm}^{2}$ ) and cultured in endothelial serum-free medium (ESFM; GIBCO) with media changes every 2-3 days. Venous differentiation was induced using $10 \mathrm{ng} / \mathrm{ml}$ epidermal growth factor (EGF; R\&D Systems), and 20 $\mathrm{ng} / \mathrm{ml}$ bFGF. For arterial differentiation, the medium was supplemented with $10 \mathrm{ng} / \mathrm{ml}$ EGF, $20 \mathrm{ng} / \mathrm{ml}$ bFGF, and $10 \mathrm{ng} / \mathrm{ml}$ VEGF. The endothelial cells were passaged using accutase (Invitrogen) when 70-80 \% confluent and characterized after 3 to 5 passages.

\section{In vivo studies}

All experiments involving handling and manipulation of animals were approved by the Institutional Animal Care and Use Committee, National University of Singapore, and the Institutional Review Board, National University of Singapore. To assess the angiogenic potential of $\mathrm{hESC}$-derived arterial and venous ECs, $1 \times 10^{6} \mathrm{hESC}$ arterial ECs (Art-ECs) or hESC venous ECs (Ven-ECs) were suspended in $200 \mu \mathrm{l}$ of growth factor-reduced Matrigel and injected subcutaneously in each side of the dorsal region of 8- to 9-week-old nonobese diabetic (NOD)/severe combined immunodeficiency (SCID) mice [NOD.CB17-Prkdc ${ }^{\text {scid } / J] ~(t w o ~ i m p l a n t s ~ p e r ~ m o u s e ; ~ t h r e e ~}$ mice per experimental condition). Matrigel plug without cells served as control. After 2 weeks, the Matrigel plug was harvested with the surrounding tissues and processed for histological analysis.

To assess the safety of hESC-derived ECs, $1 \times 10^{6} \mathrm{hESCs}$, hESC-Art-ECs, or hESC-Ven-ECs were suspended in $200 \mu \mathrm{l}$ of phosphate-buffered saline and injected subcutaneously in each side of the dorsal region of 6- to 8-week-old NOD/SCID mice [NOD.CB17-Prkdc scid/J] (two implants per mouse; three mice per experimental condition). After 4 months or formation of tumor mass $\geq 1.5 \mathrm{~cm}$ in size (whichever was earlier), the mice were sacrificed and the tissue around the point of injection was harvested and processed for histological analysis.

\section{Supplementary methods}

For additional methods refer to Additional file 1. Information related to list of primers and antibodies used in the study are presented in Additional file 1.

\section{Results}

For all the differentiation studies the H1-hESC line was used primarily, and the robustness of the protocol verified using H9-hESCs.

\section{Temporal emergence of primitive streak capable of commitment to mesoderm and endoderm}

In early embryogenesis, mesoderm that gives rise to cells of the vascular lineage arises through an epithelial- mesenchymal transition (EMT) of epiblast cells in the region of PS. For differentiation to PS, we modified our previously published protocol [17], using plasma fibronectin as substrate and CHIR99021 $(5 \mu \mathrm{M})$ to inhibit GSK-3 under chemically defined conditions. During the induction of PS, we observed a marked downregulation of the pluripotency gene $S O X 2$ within 24 hours, followed by OCT4 and NANOG, and the neuroectodermassociated genes (PAX6, SOX1) (Fig. 1a and b). In contrast to the downregulation of neuroectodermal genes, the PS-related genes (BRACHYURY, MIXL1) were upregulated synchronously along with anterior PS genes (FOXA2, GSC) and peaked at day 1 of differentiation (Fig. 1c). Furthermore, the temporal expression of PSrelated genes was accompanied by upregulation of the gene involved in EMT (SNAI1). The expression of BRACHYURY along with OCT4 after 24 hours of inhibition of GSK-3 was confirmed by immunofluorescence (Fig. 1d). Temporal expression of Brachyury accompanied with EMT suggests the emergence of Brachyury ${ }^{+}$PSlike cells at early stages of inhibition of GSK-3 as previously reported [17, 23-25].

Cells of the PS have the ability to commit to mesoderm and endodermal progenies depending on the balance between bFGF, Activin and BMP4 signaling [3, 17, 23, 26]. We next sought to ascertain the differentiation capacity of PS towards mesoderm and endoderm, as illustrated in Additional file 1 (Figures S3 and S4). Real-time PCR analysis revealed that induction with bFGF resulted in modest upregulation of lateral and paraxial mesodermal transcripts (VEGFR2, PDGFR $\alpha, P D G F R \beta$ ) accompanied by downregulation of PS and endoderm-related transcripts (FOXA2, GSC, CXCR4) (Additional file 1: Figure S3). On the contrary, treatment of PS with Activin-A resulted in marked upregulation of endodermal transcripts and downregulation of PS and mesoderm-related transcripts, while these findings were abrogated in the presence of SB431542 (Additional file 1: Figure S4). Collectively, these observations demonstrate the potential of hESCs differentiated to PS under the influence of GSK-3 inhibition (for 24 hours) to commit towards mesoderm or endoderm depending on the culture milieu provided.

\section{VEGF is essential and sufficient for endothelial commitment from early mesodermal cells, and BMP4 is synergistic}

Inhibition of GSK-3 followed by bFGF exposure drives the hESCs towards lateral plate mesoderm as evidenced by the upregulation of VEGFR2 and downregulation of PS and endoderm-related genes. We next sought to investigate the potential of these lateral plate mesoderm cells to commit towards endothelial lineage. Differentiation was performed using BMP4 and VEGF after initial treatment with CHIR99021 and bFGF as illustrated in 
Fig. 2a. The kinetics of differentiation towards endothelial lineage was monitored using VEGFR2 (an early marker for lateral plate mesoderm-derived progenitors), CD34 (early marker for progenitors with potential to differentiate towards hemato-endothelial lineage), CD31 (pan-endothelial lineage marker) and platelet-derived growth factor (PDGF)R $\beta$ (early marker for paraxial mesoderm). Real-time PCR analysis (Fig. 2b) revealed BMP4 supplementation resulted in upregulation of VEGFR2, but had minimal effect on the expression levels of CD34 and CD31. On the contrary, treatment with VEGF resulted in a modest increase in the transcript levels of CD34, CD31 and VEGFR2 and downregulation of PDGFR $\beta$, while combined modulation with BMP4 and VEGF resulted in marked upregulation of $C D 34$, CD31 and VEGFR2 and marked downregulation of PDGFR $\beta$. Furthermore, the pluripotency markers were markedly downregulated under all the three differentiation conditions (Fig. 2c). In accordance with the realtime PCR data, time-course flow cytometry analysis (Fig. 3) revealed the gradual emergence of a VEGFR2 ${ }^{+}$ population with BMP4 supplementation, but only a small subset of this population co-express CD34 ( 6.5\% on day 5), while the addition of VEGF resulted in the gradual appearance of $\mathrm{CD}^{+} 4^{+}$cells that co-express VEGFR2 and CD31 and account for $~ 54 \%$ of the differentiated cells by the fifth day of differentiation. Furthermore, combined treatment with BMP4 and VEGF resulted in a robust emergence of $\mathrm{CD} 34^{+} \mathrm{VEGFR}^{+} /$ $\mathrm{CD} 34^{+} \mathrm{CD} 31^{+}$cells which accounted for $\sim 95 \%$ of the differentiated cells by the fifth day of differentiation. In all three differentiation conditions, time-course flow cytometry plots also reveal the temporal emergence of a VEGFR2 $2^{+}$population that gradually attains CD34 and CD31 positivity. These findings suggest the role of VEGF in induction to lateral plate mesodermal progenitors (VEGFR2 ${ }^{+}$cells) and further to endothelial progenitors $\left(\mathrm{CD} 34^{+} \mathrm{CD} 31^{+} \mathrm{VEGFR}^{+}\right.$cells) and a synergistic role of $\mathrm{BMP} 4$ resulting in robust commitment to the endothelial lineage. We verified the robustness of the protocol using H9-hESCs which also yielded $~ 90 \%$ of cells positive for VEGFR2, CD34 and CD31 (Additional file 1: Figure S5). In conclusion, step-wise treatment of hESCs with GSK-3 inhibitor, bFGF followed by BMP4 and VEGF results in sequential emergence of Brachyury ${ }^{+}$PS , VEGFR2 ${ }^{+}$ early mesoderm/lateral mesoderm cells followed by robust commitment to endothelial lineage yielding 90-95\% of $\mathrm{CD}_{3} 4^{+} \mathrm{CD} 31^{+}\left(\mathrm{VEGFR}^{+}\right)$endothelial progenitor cells

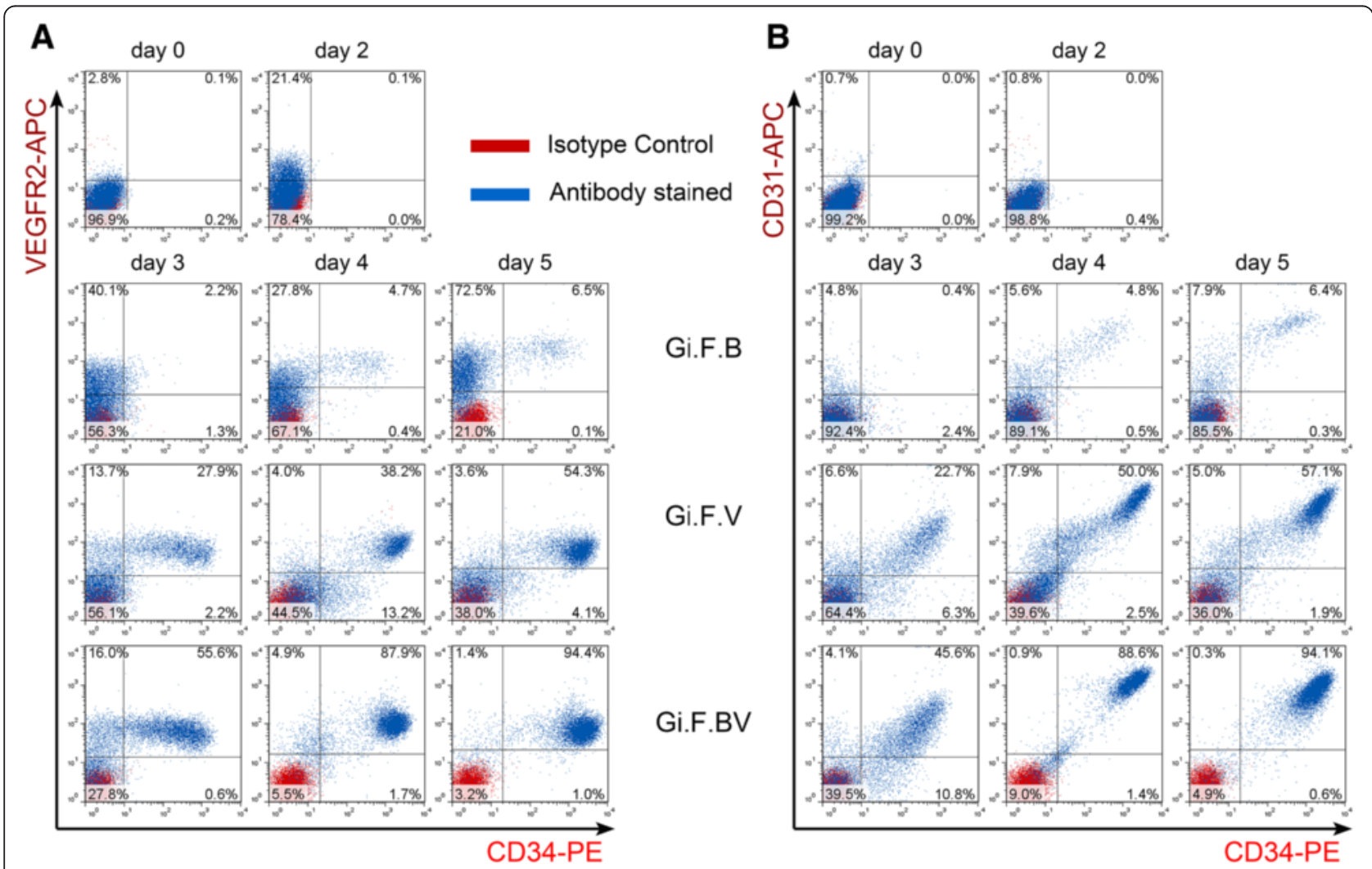

Fig. 3 Flow cytometry analysis of induction of H1-hESCs towards endothelial lineage. Representative flow cytometry overlays display the kinetics of co-expression of vascular endothelial growth factor receptor-2 (VEGFR2) and CD34 (a), and CD31 and CD34 (b) upon induction of H1-hESCs with BMP4 (Gi.F.B), VEGF (Gi.F.V) and BMP4 + VEGF (Gi.F.BV) over a differentiation period of 5 days 
within a differentiation span of 5 days under feeder-free, and chemically defined conditions.

\section{Terminal differentiation of $\mathrm{CD} 34^{+} \mathrm{CD} 31^{+}$endothelial progenitors to arterial and venous endothelial cells under serum-free conditions}

Under serum-containing conditions, high concentrations (50 ng/ml) of VEGF have been reported to aid arterial differentiation, while lower concentrations $(10 \mathrm{ng} / \mathrm{ml})$ aid venous commitment of mouse ESCs and human iPSCs [27-29]. However, differentiation of hESCs to arterial and venous ECs and, specifically, differentiation under serum-free conditions has not been reported so far. The $\mathrm{CD} 34^{+} \mathrm{CD} 31^{+}$endothelial progenitors were sorted and further differentiated towards endothelial subtypes in serum-free conditions using commercially available ESFM. Serum-containing endothelial medium typically requires supplementation with FBS (2-5\%), insulin, heparin, ascorbic acid, hydrocortisone, insulin-like growth factor, bFGF, EGF and VEGF, but the serum-free endothelial medium as per manufacturer's instructions requires supplementation with bFGF $(20 \mathrm{ng} / \mathrm{ml})$ and EGF $(10 \mathrm{ng} / \mathrm{ml})$ only. Hence we initially carried out the differentiation of the $\mathrm{CD} 34^{+} \mathrm{CD} 31^{+}$cells in ESFM supplemented with bFGF and EGF for 3-6 passages (Fig. 4a). Differentiation under these conditions yielded 98-99\% $\mathrm{CD} 4^{+} / \mathrm{CD} 31^{+} / \mathrm{VE}-\mathrm{CAD}^{+}$ECs (Fig. 4b). Real time RTPCR analysis demonstrated upregulation of all transcripts associated with endothelial lineage (Fig. 5a). Additionally, immunocytochemistry revealed the expression of CD31, $V E-C A D$ and $v W F$ (Fig. 5b). Further analysis into the arterial and venous phenotype markers showed almost $80-90 \%$ of the cells to be positive for venous markers (NRP2, EPH-B4) while only $2-10 \%$ of the cells differentiated from H1/H9-hESCs expressed NRP1 and DLL4, and $\sim 13-17 \%$ expressed CXCR4 (Fig. 4b). The endothelial, arterial and venous marker expression profiles were similar to those expressed by human umbilical vein endothelial cells (HUVECs) (Figs. 4 and 5).These observations suggest the commitment of $\mathrm{CD} 34^{+} \mathrm{CD} 31^{+}$cells towards venous endothelial phenotype and these would be referred to as hESC-Ven-ECs (H1/H9).

VEGF has been reported as critical for vascular patterning governing the specification towards arterial phenotype through a cascade of signaling events involving Shh, Notch, Dll4 and Ephrin-B2 [3, 30-32]. Similar studies on mouse ESCs $[29,30]$, human adult progenitors [33] and human iPSCs [28] have shown high concentrations of VEGF favoring arterial specification. To ascertain if the $\mathrm{CD} 34^{+} \mathrm{CD} 31^{+}$cells had the potential to commit towards arterial phenotype, we additionally supplemented the ESFM with VEGF in addition to EGF and bFGF. Surprisingly, when the $\mathrm{CD} 34^{+} \mathrm{CD} 31^{+}$cells were exposed to high concentrations of VEGF (50 ng/ml), we observed apoptosis of the cells. Titration of VEGF concentration and analysis of apoptotic cell death using AnnexinV-Propidium iodide staining revealed the occurrence of cellular apoptosis in a dose-dependent manner with the optimal concentration around 5-10 ng/ml VEGF (Additional file 1: Figure S6). Differentiation of $\mathrm{H} 1 / \mathrm{H} 9-\mathrm{hESC}$-derived $\mathrm{CD} 34^{+} \mathrm{CD} 31^{+}$cells in the presence of $10 \mathrm{ng} / \mathrm{ml} \mathrm{VEGF}$ for 3-6 passages, yielded almost 95$99 \%$ of $\mathrm{CD}^{+} 4^{+} / \mathrm{CD} 1^{+} / \mathrm{VE}-\mathrm{CAD}{ }^{+} \mathrm{ECs}$ (Fig. 4b). Flow cytometry analysis showed that these ECs were also positive for arterial markers (NRP1, DLL4, CXCR4) and only $5-6 \%$ of the cells were positive for venous markers (NRP2, EPH-B4) (Fig. 4b). When compared to Ven-ECs, H1/H9-hESC-derived endothelial progenitors differentiated under the influence of VEGF displayed significantly higher levels of CD31, vWF, eNOS and Tie2 (Fig. 5a). Real-time PCR analysis also revealed that these cells had significantly higher levels of arterial markers and lower levels of venous endothelial markers (Fig. 5a). The endothelial, arterial and venous marker expression profiles were similar to those expressed by human coronary artery endothelial cells (HCAECs) (Figs. 4 and 5). The expression profile of the cells differentiated under the influence of low concentrations of VEGF indicate the commitment of $\mathrm{CD} 34^{+} \mathrm{CD} 31^{+}$cells towards arterial endothelial phenotype and these would be referred to as hESC-Art-ECs (H1/H9). Furthermore, both hESC-ArtECs and hESC-Ven-ECs were functional in terms of their ability for acetylated low-density lipoprotein uptake and formation of cord-like structures over Matrigel (Fig. 5b).

Studies have shown that ECs commit to arterial or venous fate in early embryonic development. However, studies suggest that ECs display a certain degree of plasticity and express characteristics of alternative endothelial phenotypes [34-36]. This degree of plasticity of endothelial phenotypes is poorly understood, though studies suggest the role of hemodynamic forces, microenvironment, smooth muscle coverage, wounding and pathological conditions [34-38]. Hence, to examine whether these hESC-derived ECs are committed to an arterial or venous fate, we cross-cultured the hESCderived arterial ECs in venous media conditions (i.e., in the absence of VEGF) and hESC-derived venous ECs in arterial media conditions by supplementing the medium with VEGF. Both H1- and H9-hESC-derived arterial ECs, upon culture under venous conditions for two passages, resulted in a $15-25 \%$ reduction in the number of ECs expressing arterial markers (NRP1 and DLL4) and were associated with a $12-20 \%$ increase in the number of ECs expressing venous markers (NRP2 and EPH-B4) (Additional file 1: Figure S7). Similarly, culture of H1- and H9-hESC-derived venous ECs under arterial conditions for two passages resulted in a $15-20 \%$ reduction in the 


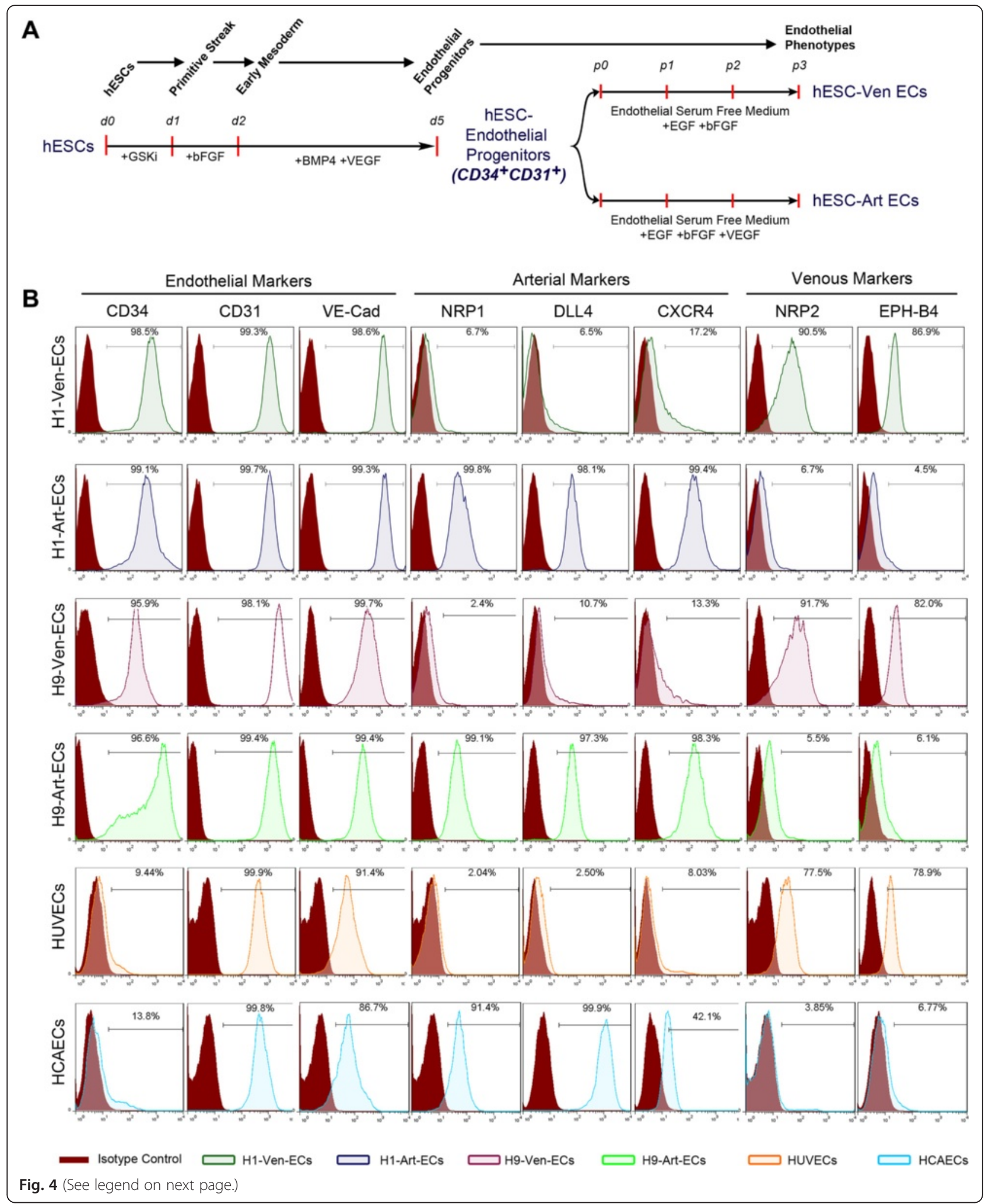


(See figure on previous page.)

Fig. 4 Flow cytometry characterization of terminal differentiation of $\mathrm{CD} 34^{+} \mathrm{CD} 31^{+}$endothelial progenitors to venous and arterial endothelial cells under serum-free conditions. a Schematic representation of differentiation of hESCs to endothelial progenitors and further differentiation towards venous ECs ( $h E S C$-Ven-ECs) and arterial ECs (hESC-Art-ECs). b Representative flow cytometry histogram overlays represent the expression of pan-endothelial, arterial and venous markers among H1-Ven-ECs, H1-Art-ECs, H9-Ven-ECs, H9-Art-ECs, HUVECs, and HCAECs. bFGF Basic fibroblast growth factor, BMP4 Bone morphogenetic protein 4, EGF Epidermal growth factor, GSKi Glycogen synthase kinase inhibitor (CHIR99021), HCAEC Human coronary artery endothelial cells, hESC Human embryonic stem cells, HUVEC Human umbilical vein endothelial cells, VEGF Vascular endothelial growth factor

number of ECs expressing venous markers and was associated with a 7-15\% increase in the number of ECs expressing arterial markers. Hence, the changes in culture conditions resulted in transition of a small subset of the arterial ECs to venous phenotype and vice versa.

In summary, we developed a protocol that results in rapid and efficient differentiation of hESCs to $\mathrm{CD} 34^{+} \mathrm{CD} 31^{+}$ endothelial progenitors with the potential to commit to arterial and venous endothelial phenotypes under feeder- and serum-free conditions through modulating the concentration of VEGF.

\section{Intrinsic differences in cell migration and angiocrine secretome profiles of hESC-derived arterial and venous ECs}

ECs interact with the local microenvironment and support tissue regeneration after injury through revascularization of the newly healed tissue and expression of various trophic growth factors, known as angiocrine factors, which lead to proliferation and migration of ECs from pre-existing blood vessels. To assess cell migration, in vitro wound closing assays were performed over a period of 24 hours. Compared to H1-Ven-ECs, the H1Art-ECs displayed faster closure of the wound area resulting in a complete wound closure by $\mathrm{H} 1$-Art-ECs in $\sim 15$ hours in contrast to $\sim 27$ hours taken by H1-VenECs (Fig. 6a). Similarly, the H9-Art-ECs and HCAECs displayed faster closure of the scratch wound compared to respective venous phenotypes (Fig. 6a). ECs pertaining to distinct vascular beds have recently been reported to display significant differences in expression profiles of various transcriptomes, angiocrine factors and surface markers [39]. However, the distinct expression of various angiocrine factors by different endothelial phenotypes of hESC origin still needs to be explored. To probe into the profile of various angiocrine factors secreted by hESCderived ECs, we used angiogenesis antibody array of 55 different proteins related to angiogenesis, growth factors and related proteins, cytokines, proteases and their inhibitors, neurotrophic factors, and anti-angiogenic factors. Both H1-Art-ECs and H1-Ven-ECs displayed marked induction of endothelin-1, insulin-like growth factorbinding protein-2 (IGFBP-2), monocyte chemoattractant protein-1 (MCP-1), pentraxin-3, serpin-E1 and tissue inhibitor of matrix metalloproteinase-1 (TIMP-1) (Fig. 6;
Additional file 1: Figure S7 and Table S1). However, the conditioned media of H1-Ven-ECs had significantly higher levels of Activin-A, IGFBP-3, and interleukin-1 $\beta$ compared to H1-Art-ECs (Fig. 6c). On the contrary, the media conditioned by $\mathrm{H} 1$-Art-ECs had significantly higher levels of IGFBP-1, interleukin-8, matrix metalloproteinase-9 (MMP-9), PDGF-AA and thrombospondin-1 (TSP-1) compared to that of H1-Ven-ECs (Fig. 6c). These results emphasize the existence of intrinsic differences between arterial and venous endothelial phenotypes. However, further studies on the differences in secretome profiles among the two endothelial phenotypes and their in vivo relevance are needed to understand the role of endothelial heterogeneity.

\section{Transplantation of hESC-derived arterial and venous ECs result in formation of microvessels}

After assessment of the in vitro functionality of the hESC-derived arterial and venous ECs, we investigated whether these ECs have the ability to form functional microvessels upon transplantation, by injecting ECs suspended in Matrigel subcutaneously into the dorsal region of immunodeficient mice. Matrigel plugs implanted without cells exhibited no evidence of microvessels within the matrix (Fig. 7a). On the other hand, the Matrigel plugs implanted along with hESC-Art-ECs or hESC-Ven-ECs showed the presence of microvessels within the matrix. Additionally, these microvessels were seen to be connected to the host circulation, as evidenced by the presence of red blood cells within the lumen (Fig. 7a). Furthermore, these microvessels were reactive for anti-human CD31 and anti-human collagen$\mathrm{IV}$, indicating that they were of human origin (Fig. 7b). Furthermore, the hESC-Art-ECs and hESC-Ven-ECs largely maintained their respective phenotypes in vivo, as evidenced by the expression of Ephrin-B2 and Eph-B4, respectively (Fig. 7b). However, few microvessels formed by hESC-Art-ECs showed the expression of venous markers and vice versa.

To determine if the hESC-derived arterial and venous ECs have tumorogenic potential, we transplanted $\mathrm{H} 1$ hESC-derived arterial and venous ECs and their cell source (H1-hESCs) into immunocompromised mice. All the mice injected with H1-hESCs developed teratomas within 3-4 months of transplantation, while none of 


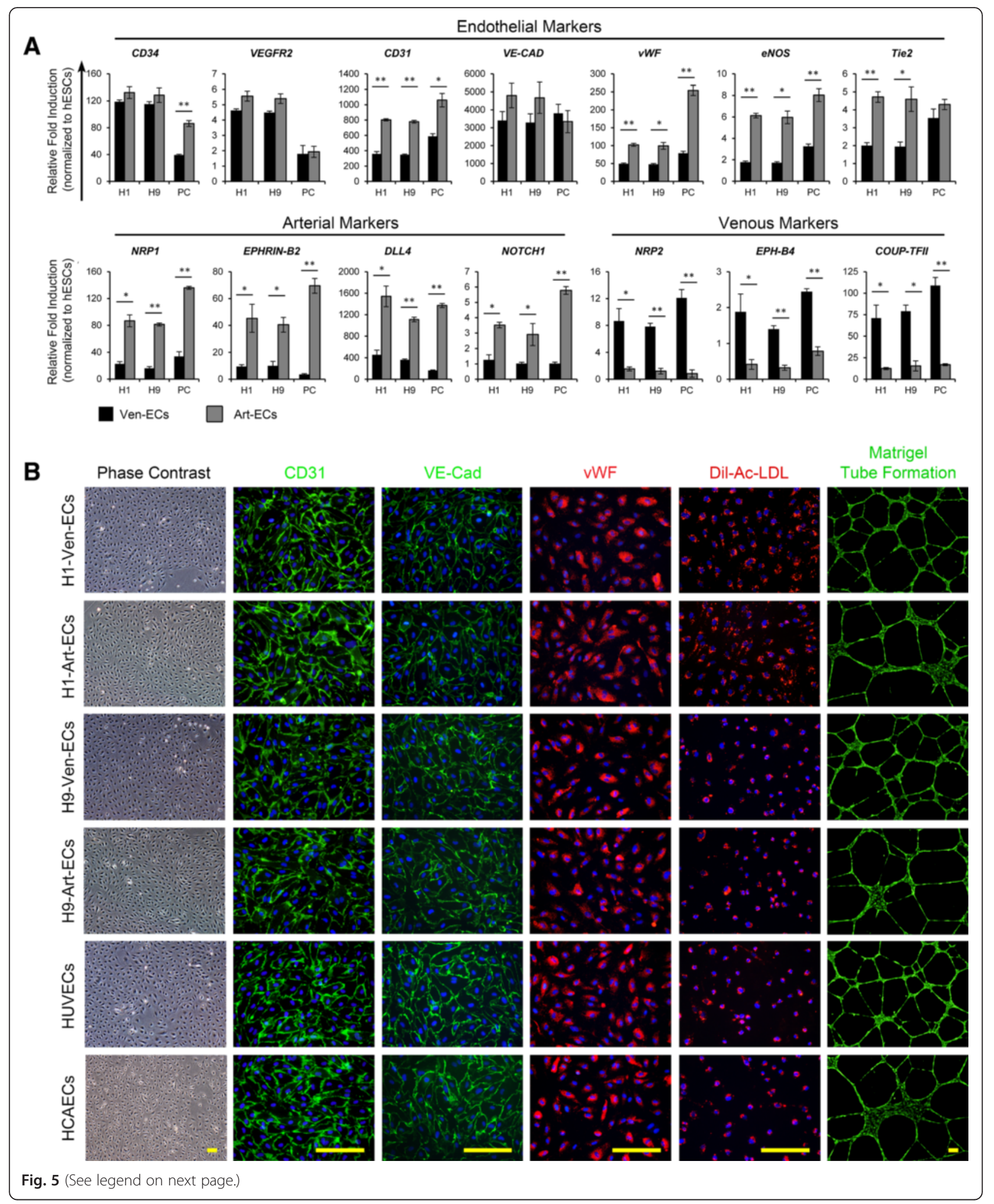


(See figure on previous page.)

Fig. 5 Characterization of hESC-derived venous and arterial endothelial cells. a Profiles of transcripts related to endothelial, arterial and venous phenotypes among Ven-ECs and Art-ECs derived from H1-hESCs, H9-hESCs and primary cells (PC: HUVECs and HCAECs). Gene expression levels were normalized to corresponding $\beta$-ACTIN values and are represented as relative to undifferentiated hESCs. b Representative photomicrographs of H1-Ven-ECS, H1-Art-ECs, H9-Ven-ECs, H9-Art-ECs, HUVECS, and HCAECs show the cobblestone morphology of ECs under phase contrast microscopy, and immunofluorescence images demonstrate the expression of pan-endothelial markers CD31, VE-Cadherin, and von Willebrand factor (vWF), uptake of Dil-acetylated low-density lipoprotein (Dil-Ac-LDL) and formation of cord-like structures over Matrigel (Green-CalceinAM). Scale bars $=150 \mu \mathrm{m}$. Error bars show standard deviation; $n \geq 3 .{ }^{*} p<0.05,{ }^{* *} p<0.01$. Art-EC Arterial endothelial cells, HCAEC Human coronary artery endothelial cells, $h E S C$ Human embryonic stem cells, HUVEC Human umbilical vein endothelial cells, Ven-EC Venous endothelial cells

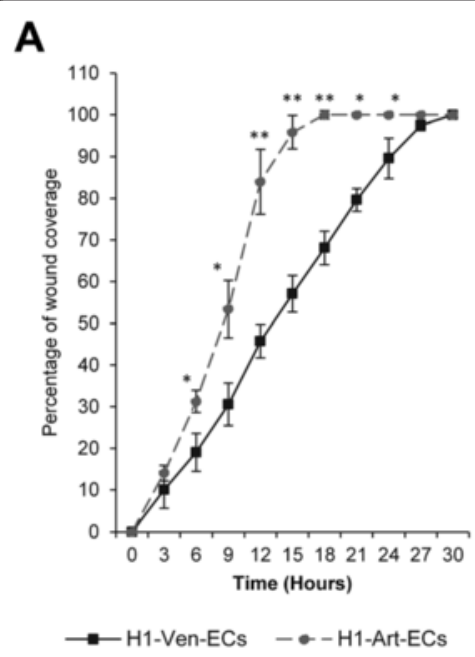

B

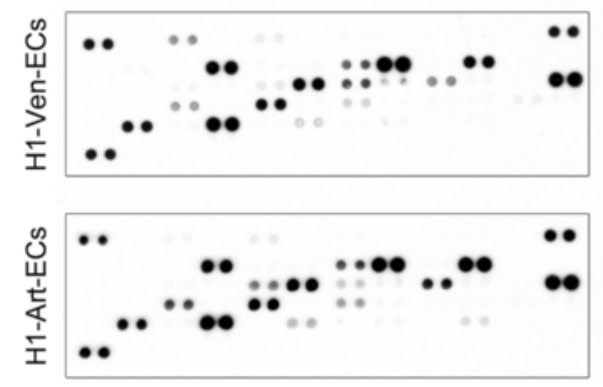

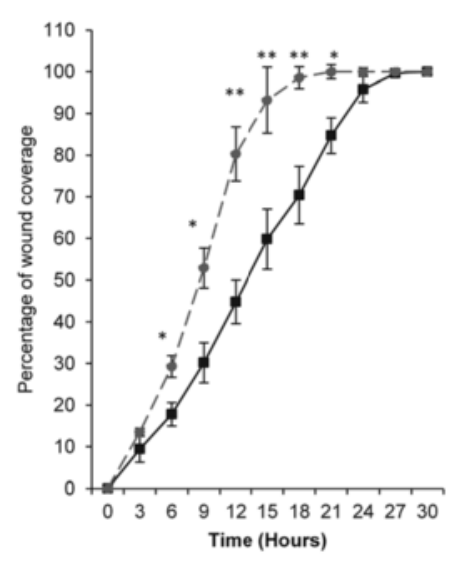

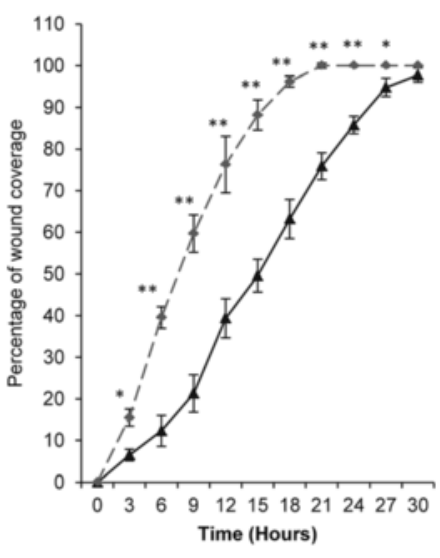

$\multimap$ HUVECS - - HCAECS

C

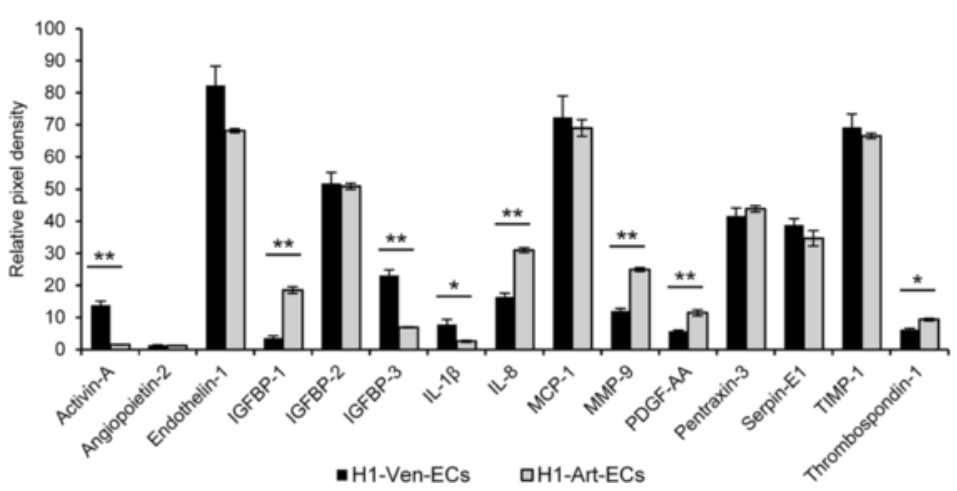

Fig. 6 Assessment of cell migration and survey of angiocrine secretome profiles of hESC-derived arterial and venous ECs. a Graphical representation of kinetics of wound coverage among H1-Ven-ECs and H1-Art-ECs (left panel), H9-Ven-ECs and H9-Art-ECs (middle panel), HUVECs, and HCAECs (right panel). Error bars show standard deviation; $n=3 .{ }^{*} p<0.05,{ }^{* *} p<0.01$. b Representative scans of angiogenesis antibody arrays demonstrating the secretion of various angiocrine factors by $\mathrm{H} 1$-Ven-ECs and $\mathrm{H} 1$-Art-ECs. Array images are obtained from 10-minute exposure of X-ray film. (Refer to Additional file 1 for co-ordinates of the antibody array). c Graphical representation of the relative amounts of selected angiocrine factors that show significant differences among the $\mathrm{H} 1$-hESC derived arterial and venous ECs. The bars represent relative amounts of factors secreted based on densitometric analysis of relative pixel density of the blots. Error bars show the standard deviation of two independent experiments. ${ }^{*} p<0.05,{ }^{* *} p<0.01$. Art-EC Arterial endothelial cells, HCAEC Human coronary artery endothelial cells, hESC Human embryonic stem cells, HUVEC Human umbilical vein endothelial cells, IGF Insulin-like growth factor, IL Interleukin, MCP monocyte chemoattractant protein, MMP Matrix metalloproteinase, PDGF Platelet-derived growth factor, TIMP Tissue inhibitor of matrix metalloproteinase, Ven-EC Venous endothelial cells 


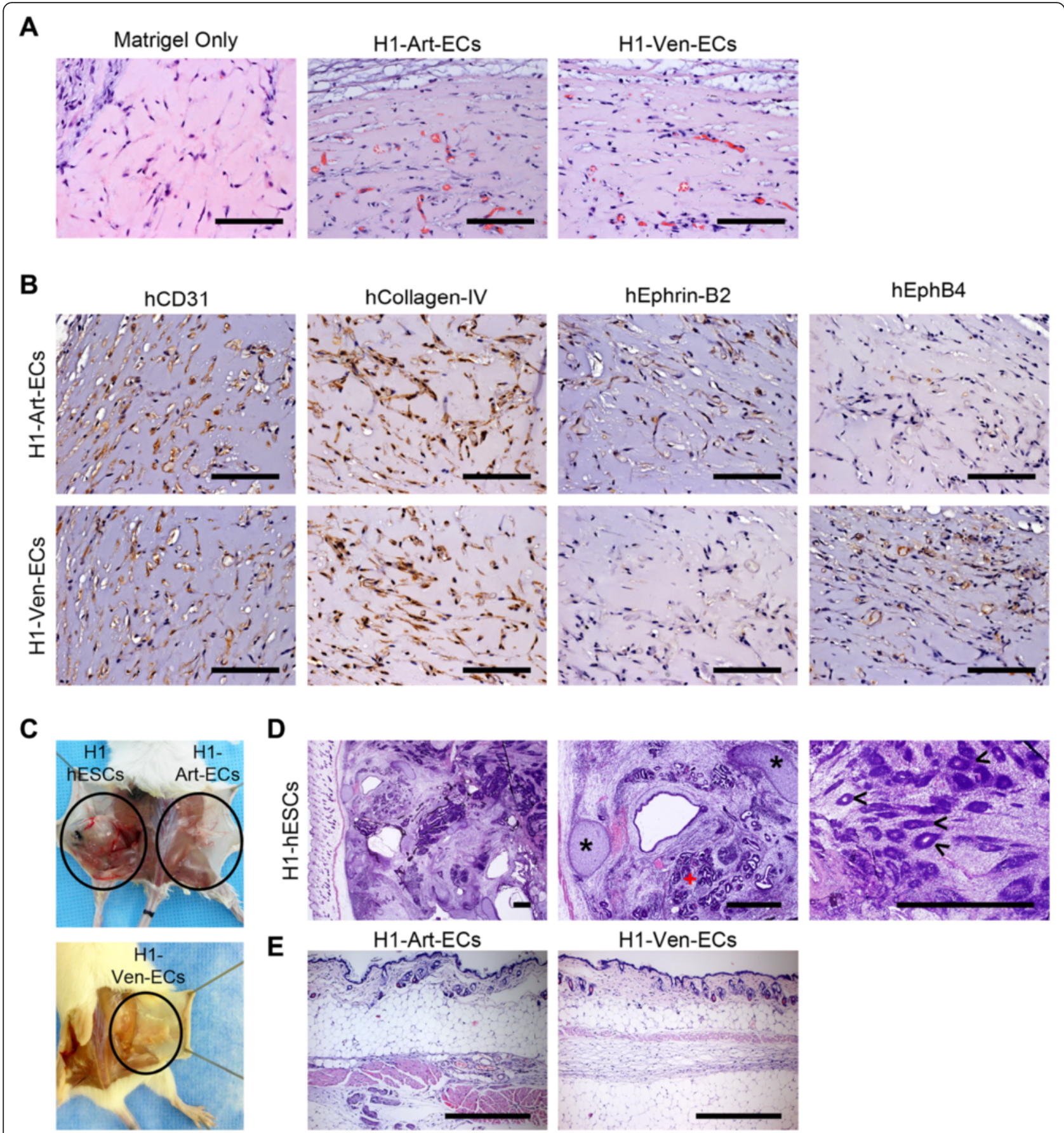

Fig. 7 In vivo safety and functionality assessment of hESC-derived arterial and venous endothelial cells. a Representative hematoxylin and eosin (H\&E) stained micrographs of Matrigel plug study showing absence of microvessels in Matrigel-only control, while the others show the formation of perfused microvessels by engrafted hESC-derived arterial and venous ECs. b Histochemical micrographs of microvessels formed by hESC-derived arterial and venous ECs stained for hCD31, hCollagen-IV, hEphrin-B2 and hEph-B4. c Representative photographs showing the presence or absence of teratoma formation in immunodeficient mice. $\mathbf{d}$ Representative H\&E stained micrographs showing the formation of teratoma by H1-hESCs with evidence of differentiation to derivatives of three germ layers: ectoderm (hair follicles, $<$ ), mesoderm (cartilage, ${ }^{*}$ ), and endoderm (glandular structures, +). e Representative H\&E stained micrographs showing the absence of teratoma formation by H1-hESCs derived arterial and venous ECs. Scale bars in (a) and (b) $=100 \mu \mathrm{m}$; in (d) and $(\mathbf{e})=500 \mu \mathrm{m}$. Art-EC Arterial endothelial cells, hESC Human embryonic stem cells, Ven-EC Venous endothelial cells 
those that received either of the ECs showed sign of teratoma for the same period of time (Fig. 7c-e). Hence, the hESC-derived arterial and venous ECs differentiated under feeder- and serum-free conditions were functional and non-tumorogenic in-vivo.

\section{Discussion}

In the present study, we demonstrate a novel and efficient protocol for monolayer differentiation of hESCs towards arterial and venous ECs under feeder- and serumfree conditions. These hESC-derived arterial and venous ECs demonstrate differences in gene expression and angiocrine secretion profiles, and form functional microvessels in vivo. Despite tremendous progress in the differentiation of hESCs to ECs, current protocols are inefficient predominantly due to a poorly controlled differentiation microenvironment and lack of the concept of a lineage-directed approach [5]. We [17] and others $[23,24,40-43]$ have demonstrated that activation of the Wnt/ $\beta$-Catenin pathway with or without BMP4 and Activin-A efficiently drives the differentiation of PSCs towards mesoderm and endoderm lineages. Cao et al. demonstrated the robust differentiation of PSCs to cardiovascular progenitors upon combined treatment with BMP4, CHIR99021 and ascorbic acid in a chemically defined medium under feeder- and serum-free culture conditions [44]. Similarly, a recent report demonstrates a robust commitment of human iPSCs towards mesoderm in the presence of the GSK-3 inhibitor CHIR99021 followed by induction to cardiac progenitors upon $\beta$ Catenin siRNA knockdown, suggesting a dual function of the Wnt/ $\beta$-Catenin pathway during early cardiovascular development [45]. In this study, we directed the hESCs towards lateral plate mesoderm under feeder-free and chemically defined conditions through short-term inhibition of GSK-3 followed by treatment with bFGF and BMP4. Currently available protocols to differentiate hESC and hiPSCs towards endothelial lineage generally requires 10-15 days of differentiation to achieve a modest $2-40 \%$ of progenitor cells committed to endothelial lineage [5]. Recent reports show commitment of hESCs to endothelial lineage with $\sim 50 \%$ efficiency by using GSK-3 inhibition and treatment with BMP4 at early stages of differentiation, followed by treatment with BMP4 and inhibition of Notch/TGF $\beta$ signaling pathways $[17,40]$. Though a detailed comparison with published protocols was not undertaken, our current findings suggest a robust commitment (90-95\%) towards endothelial lineage within a differentiation span of 5 days. Furthermore, the differentiation protocol primarily results in generation of $\mathrm{CD} 34^{+} \mathrm{CD} 31^{+}$cells, in comparison to previously published methods which generates a mixture of $\mathrm{CD} 34^{+} \mathrm{CD} 31^{-}, \mathrm{CD} 34^{-} \mathrm{CD} 31^{+} \mathrm{CD} 34^{+} \mathrm{CD} 31^{+}$and $\mathrm{CD} 4^{-} \mathrm{CD} 31^{-}$cells $[46,47]$. The robustness of our endothelial differentiation protocol was verified among two different hESC lines; however, it needs further validation using other hESC lines and iPSCs.

Distinction of arterial and venous endothelial phenotypes seems to occur quite early in the development even before the onset of circulation, wherein VEGF, Shh, and Notch signaling have been suggested to play a crucial role [31, 32]. In vitro studies using mouse PSCs [29, 48] indicate the expression of arterial markers such as Dll4, EphrinB2 and Notch4 in response to high concentrations of VEGF (50 ng/ml), while lower concentrations (10 ng/ $\mathrm{ml}$ ) resulted in upregulation of the venous marker COUPTFII. Additionally, the VEGF-mediated arterialization was reported to be further enhanced by the addition of adrenomedullin $[27,48]$ and these effects were blocked in the absence of Notch signaling $[27,29]$. These findings from in vitro models correlate with the findings of in vivo animal models highlighting the coordinated activation of VEGF-Notch signaling in arterial specification. Though tremendous amounts of information have been obtained from in vitro human models, the heterogeneity of ECs and/or derivation of tissue-specific ECs have been investigated by very few studies. Human cord blood-derived endothelial progenitors [49] and hPSCs [50, 51] upon coculture with neural cells differentiate to brain-specific ECs and express markers and functions related to the bloodbrain barrier. Recent studies based on plastic conversion of fibroblasts to ECs and iPSC-derived ECs reported the pool of terminally differentiated ECs as being heterogeneous in terms of expression of arterial, venous and lymphatic markers $[52,53]$. However, distinct specification towards either phenotype is not investigated. Only two studies using human adult progenitors [33] and human iPSCs [28] have elucidated the arterial-venous specification of human progenitor/stem cells to date. Aranguren et al. reported that a high concentration of VEGF $(100 \mathrm{ng} / \mathrm{ml})$ induced arterial differentiation of human bone marrowderived multipotent adult progenitor cells [33]. Furthermore, the arterial induction was reported to be enhanced by supplementation with Dll4 and Shh, while blockade of Notch and/or Shh led to attenuation of arterial differentiation and upregulation of venous markers. Similarly, Rufaihah et al, using human iPSCs, demonstrated arterial differentiation by high VEGF concentration coupled with CAMP, and induction of venous specification under low concentrations of VEGF [28]. In summary, all the above studies in mouse and human in vitro models indicate the dose-dependent effect of VEGF in arterial-venous specification of ECs; however, these studies were performed under serum-containing conditions.

Inclusion of xenogeneic products (like Matrigel, FBS, murine stromal cells) in the culture milieu could influence the differentiation outcome and limit the ability to tune the microenvironment due to the presence of 
unknown/poorly defined factors [16]. To eliminate or reduce the use of xenogeneic products, we have developed a novel feeder- and serum-free protocol for differentiation of hESCs to endothelial subtypes. Under serumfree conditions, we found higher concentrations of VEGF (25-100 $\mathrm{ng} / \mathrm{ml}$ ) caused apoptosis of the cells, while at lower concentrations $(10 \mathrm{ng} / \mathrm{ml})$ it directs towards the arterial phenotype and in its absence favors the venous fate. Spatially different response of hESCderived endothelial progenitors to various concentrations of VEGF is in contrast to the findings previously reported under serum-containing conditions which could be due the presence of serum in the culture milieu. These novel insights into the arterial-venous specification under serum-free conditions could provide clues for developing clinically competent vascular cells in the future. However, in the current methodology, the hESCs cultured in mTeSR1 over Matrigel were used. Matrigel is of murine origin and mTeSR1 contains certain components of xenogeneic origin. Secondly, both $\mathrm{H} 1$ and $\mathrm{H} 9 \mathrm{hESCs}$ used in the current study were originally derived under xenogeneic conditions. Matrigel-based feeder-free culture systems have been successfully replaced with the use of xeno-free matrices and culture media [54-59]. Hence, future studies using hESCs and iPSCs derived and cultured under xeno-free conditions are warranted for derivation of clinically competent ECs.

From a drug discovery and clinical therapeutic standpoint, we reduced the use of xenogeneic products and further demonstrated the safety and the ability of hESCderived arterial and venous ECs to form microvessels upon transplantation in a mouse model. Microvessels derived from arterial and venous endothelial phenotypes were functionally integrated with the host vasculature. Furthermore, the hESC-derived arterial and venous ECs maintained the expression of the arterial marker (Ephrin-B2) and venous marker (Eph-B4), respectively. However, a few microvessels formed by arterial ECs expressed the venous marker and vice versa, which might indicate either the ECs were not sufficiently pure enough or they underwent a phenotypic change in vivo-both possibilities are equally plausible. Flow cytometry analysis of the arterial and venous markers among the ECs show that a small proportion of venous ECs express arterial markers de novo, and the proportion of these venous ECs expressing arterial markers increases upon culture under arterial conditions (and vice versa). From a phenotypic stability standpoint, ECs (especially arterial ECs) require the support of mural cells

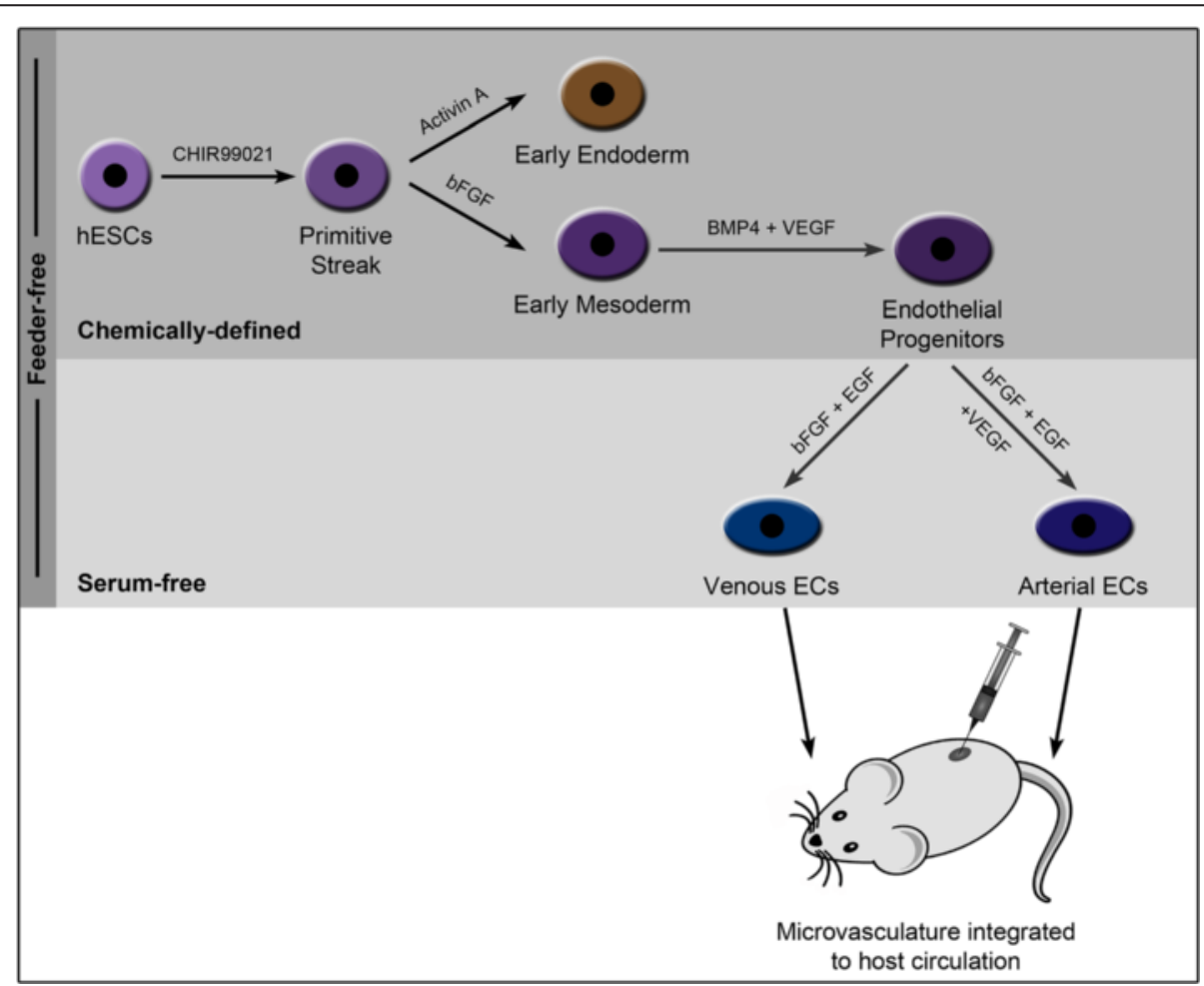

Fig. 8 Schematic diagram summarizing the protocol for differentiation of hESCS to endothelial phenotypes. Schematic representation depicts the differentiation of hESCs to endothelial progenitors and further towards venous and arterial endothelial phenotypes that upon transplantation form functional microvessels in vivo. bFGF Basic fibroblast growth factor, BMP4 Bone morphogenetic protein 4, EC Endothelial cells, EGF Epidermal growth factor, hESC Human embryonic stem cells, VEGF Vascular endothelial growth factor 
such as pericytes and vascular smooth muscle cells [3]. In the present study, only ECs (arterial or venous) were transplanted and were harvested after 2 weeks; thus, investigating the effect of absence or inclusion of supporting mural cells on the phenotypic stability/modulation would be interesting. Also, the phenotypic stability/ modulation of these microvessels after long-term integration in the in vivo milieu would be of interest to understand the arterial-venous specification and modulation. Furthermore, it needs to be determined whether the enrichment of arterial or venous subtypes favors therapeutic benefit over a mixed population of ECs. It might also be plausible that both cells types have specific indications depending on the therapeutic site or diseased state as it is well known that endothelial phenotypes contribute to site-specific predisposition and/or occurrence of vascular diseases including atherosclerosis, vascular calcifications, thrombosis and aneurysms. Furthermore, the role of these endothelial subtypes in tissue engineering of vascular stents (specifically arterial or venous stents) would be exciting. These investigations would be interesting and warranted, but are beyond the scope of this study.

\section{Conclusion}

In conclusion, we demonstrate the efficient differentiation of hESCs to $\mathrm{CD} 34^{+} \mathrm{CD} 31^{+}$endothelial progenitors under feeder-free and chemically defined microenvironment by recapitulating the early embryonic vasculogenesis through the sequential intervention of GSK-3, bFGF, BMP4 and VEGF signaling pathways that results in successive emergence of PS, early mesoderm/lateral plate mesoderm, and endothelial progenitors (Fig. 8). Under feeder- and serum-free conditions, these hESCderived endothelial progenitors could be directed to arterial and venous ECs depending on the presence or absence of VEGF. Furthermore, these hESC-derived arterial and venous ECs demonstrate differences at the transcriptome and secretome levels, and form functional microvessels that integrate with the host circulation and maintain their respective phenotypes in vivo. The efficient generation of these $\mathrm{hESC}$-derived endothelial progenitors and endothelial phenotypes may be more amenable for large-scale production and expansion. Furthermore, we believe that the findings of our study could be translated using other hESCs and iPSCs for developing personalized cell therapy, drug discovery and disease-modeling applications. Furthermore, the access to robust differentiation of human PSCs to arterial and venous ECs under defined conditions could provide a potential human model to study arterialvenous specification for various basic and pharmaceutical research applications and in the future towards clinical regenerative therapies.

\section{Additional file}

\begin{abstract}
Additional file 1: Figure S1. Immunocytochemical analysis of pluripotency status of hESCs cultured over Matrigel. Figure S2. Immunocytochemical analysis of pluripotency status of hESCs cultured over fibronectin. Figure S3. Time-course analysis of early differentiation of hESCs towards mesodermal lineage. Figure S4. Time-course analysis of early differentiation of hESCs towards endodermal lineage. Figure S5. Differentiation of H9-hESCs towards endothelial lineage. Figure S6. Effect of VEGF on hESC-derived endothelial cells under serum-free conditions. Figure S7. Survey of angiocrine secretory profile of arterial and venous ECs using angiogenesis antibody array. Table S1: Legend of coordinates for the human angiogenesis array. Table S2. Sequences of primers used for real-time RT-PCR. Table S3. List of antibodies used for flow cytometry. Table S4. List of antibodies used for immunocytochemistry. Supplementary Methods. (PDF 17154 kb)
\end{abstract}

\section{Abbreviations}

Art-EC: Arterial endothelial cells; bFGF: Basic fibroblast growth factor; BMP4: Bone morphogenetic protein 4; CAMP: Cyclic adenosine monophosphate; EC: Endothelial cells; ECM: Extracellular matrix; EGF: Epidermal growth factor; EMT: Epithelial-mesenchymal transition; ESFM: Endothelial serum-free medium; FBS: Fetal bovine serum; GSK-3: Glycogen synthase kinase-3; HCAEC: Human coronary artery endothelial cells; hESC: Human embryonic stem cells; HUVEC: Human umbilical vein endothelial cells; IGF: Insulin-like growth factor; iPSC: Induced pluripotent stem cell; PDGF: Platelet-derived growth factor; PS: Primitive streak; PSC: Pluripotent stem cells; RT-PCR: Reverse transcriptase-polymerase chain reaction; Shh: Sonic hedgehog; TGF: Transforming growth factor; VECAD: Vascular endothelial cadherin; VEGF: Vascular endothelial growth factor; VEGFR2: Vascular endothelial growth factor receptor-2; VenEC: Venous endothelial cells; vWF: von Willebrand factor.

\section{Competing interests}

The authors declare that they have no competing interests.

\section{Authors' contributions}

SG conceptualized and designed the study, performed all the cell culture, molecular and mouse studies, collected, interpreted and analyzed data, and drafted the manuscript. TJY assisted in conceptualization and design of the study, data collection/analysis and editorial support for the manuscript. II assisted in data interpretation/analysis, and provided financial and editorial support for the manuscript. RAJ assisted in supervision, data interpretation/ analysis, and editorial support for the manuscript. CT supervised the study, assisted in data interpretation/analysis, provided financial and editorial support, and approved the final manuscript. All authors read and approved the final manuscript.

\section{Acknowledgements}

The authors thank Paul Hutchinson and Guo Hui Teo for their support in flow cytometry. This work was partially supported by grants from the National University Health System (R221000053515) and the Ministry of Education, Singapore (R221000023112, R223000024133). SG was supported by a NUS Research Scholarship and President Graduate Fellowship.

\section{Author details}

${ }^{1}$ Oral Sciences Disciplines, Faculty of Dentistry, National University of Singapore, Singapore 119083, Singapore. ${ }^{2}$ Institute of Medical Biology, Agency for Science, Technology and Research (A*STAR), 8A Biomedical Groove, \#06-06 Immunos, Singapore 138648, Singapore. ${ }^{3}$ Oral and Maxillofacial Surgery Disciplines, Faculty of Dentistry, National University of Singapore, Singapore 119083, Singapore. ${ }^{4}$ Cardiac, Thoracic and Vascular Surgery (CTVS) Laboratory, Department of Surgery, Yong Loo Lin School of Medicine, National University of Singapore, Singapore 117510, Singapore. ${ }^{5}$ Singapore-Technion Alliance For Research and Technology (START) Regenerative Medicine Laboratory, Campus for Research Excellence And Technological Enterprise (CREATE), Singapore 138602, Singapore. ${ }^{6}$ NUS Graduate School for Integrative Science and Engineering, Singapore 117456, Singapore. ${ }^{7}$ Tissue Engineering Program, Life Sciences Institute, National University of Singapore, Singapore 117456, Singapore. 
Received: 27 March 2015 Revised: 25 August 2015 Accepted: 26 August 2015 Published online: 30 December 2015

\section{References}

1. Torres-Vazquez J, Kamei M, Weinstein BM. Molecular distinction between arteries and veins. Cell Tissue Res. 2003;314(1):43-59. doi:10.1007/s00441-003-0771-8

2. Aird WC. Phenotypic heterogeneity of the endothelium: II. Representative vascular beds. Circ Res. 2007;100(2):174-90. doi:10.1161/01.RES.0000255690. 03436.ae.

3. Coultas L, Chawengsaksophak K, Rossant J. Endothelial cells and VEGF in vascular development. Nature. 2005;438(7070):937-45. doi:10.1038/nature04479.

4. Rosa V, Toh WS, Cao T, Shim W. Inducing pluripotency for disease modeling, drug development and craniofacial applications. Expert Opin Biol Ther. 2014;14(9):1233-40. doi:10.1517/14712598.2014.915306.

5. Kane NM, Xiao Q, Baker AH, Luo Z, Xu Q, Emanueli C. Pluripotent stem cell differentiation into vascular cells: a novel technology with promises for vascular re(generation). Pharmacol Ther. 2011;129(1):29-49.

6. Mercola M, Colas A, Willems E. Induced pluripotent stem cells in cardiovascular drug discovery. Circ Res. 2013;112(3):534-48. doi:10.1161/CIRCRESAHA.111.250266.

7. Vinoth K, Manikandan J, Sethu S, Balakrishnan L, Heng A, Lu K, et al. Evaluation of human embryonic stem cells and their differentiated fibroblastic progenies as cellular models for in vitro genotoxicity screening. J Biotechnol. 2014;184:154-68. doi:10.1016/j.jbiotec.2014.05.009.

8. Ferreira LS, Gerecht S, Shieh HF, Watson N, Rupnick MA, Dallabrida SM, et al Vascular progenitor cells isolated from human embryonic stem cells give rise to endothelial and smooth muscle like cells and form vascular networks in vivo. Circ Res. 2007;101(3):286-94.

9. Li Z, Wilson KD, Smith B, Kraft DL, Jia F, Huang M, et al. Functional and transcriptional characterization of human embryonic stem cell-derived endothelial cells for treatment of myocardial infarction. PLoS One. 2009;4(12):e8443.

10. James D, Nam HS, Seandel M, Nolan D, Janovitz T, Tomishima M, et al. Expansion and maintenance of human embryonic stem cell-derived endothelial cells by TGFbeta inhibition is Id1 dependent. Nat Biotechnol. 2010;28(2):161-6.

11. Levenberg S, Ferreira LS, Chen-Konak L, Kraehenbuehl TP, Langer R. Isolation, differentiation and characterization of vascular cells derived from human embryonic stem cells. Nat Protoc. 2010;5(6):1115-26.

12. Hill KL, Obrtlikova P, Alvarez DF, King JA, Keirstead SA, Allred JR, et al. Human embryonic stem cell-derived vascular progenitor cells capable of endothelial and smooth muscle cell function. Exp Hematol. 2010;38(3):246-57. e1.

13. Rufaihah AJ, Huang NF, Jame S, Lee JC, Nguyen HN, Byers B, et al. Endothelial cells derived from human iPSCS increase capillary density and improve perfusion in a mouse model of peripheral arterial disease. Arterioscler Thromb Vasc Biol. 2011;31(11):e72-9. doi:10.1161/ATVBAHA.111.230938.

14. Margariti A, Winkler B, Karamariti E, Zampetaki A, Tsai TN, Baban D, et al. Direct reprogramming of fibroblasts into endothelial cells capable of angiogenesis and re-endothelialization in tissue-engineered vessels. Proc Natl Acad Sci U S A. 2012:109(34):13793-8. doi:10.1073/pnas.1205526109.

15. White MP, Rufaihah AJ, Liu L, Ghebremariam YT, Ivey KN, Cooke JP, et al. Limited gene expression variation in human embryonic stem cell and induced pluripotent stem cell-derived endothelial cells. Stem Cells. 2013; 31(1):92-103. doi:10.1002/stem.1267.

16. Kaupisch A, Kennedy L, Stelmanis V, Tye B, Kane NM, Mountford JC, et al. Derivation of vascular endothelial cells from human embryonic stem cells under GMP-compliant conditions: towards clinical studies in ischaemic disease. J Cardiovasc Transl Res. 2012;5(5):605-17. doi:10.1007/s12265-012-9379-2

17. Tan JY, Sriram G, Rufaihah AJ, Neoh KG, Cao T. Efficient derivation of lateral plate and paraxial mesoderm subtypes from human embryonic stem cells through GSKi-mediated differentiation. Stem Cells Dev. 2013;22(13):1893-906. doi:10.1089/scd.2012.0590.

18. Heng BC, Haider H, Sim EK, Cao T, Ng SC. Strategies for directing the differentiation of stem cells into the cardiomyogenic lineage in vitro. Cardiovasc Res. 2004;62(1):34-42. doi:10.1016/j.cardiores.2003.12.022.
19. Kidwai FK, Liu H, Toh WS, Fu X, Jokhun DS, Movahednia MM, et al. Differentiation of human embryonic stem cells into clinically amenable keratinocytes in an autogenic environment. J Invest Dermatol. 2013;133(3):618-28. doi:10.1038/jid.2012.384

20. Fu X, Toh WS, Liu H, Lu K, Li M, Cao T. Establishment of clinically compliant human embryonic stem cells in an autologous feeder-free system. Tissue Eng Part C Methods. 2011;17(9):927-37. doi:10.1089/ten.TEC.2010.0735.

21. Ng ES, Davis R, Stanley EG, Elefanty AG. A protocol describing the use of a recombinant protein-based, animal product-free medium (APEL) for human embryonic stem cell differentiation as spin embryoid bodies. Nat Protoc. 2008:3(5):768-76. doi:10.1038/nprot.2008.42.

22. Naujok O, Lentes J, Diekmann U, Davenport C, Lenzen S. Cytotoxicity and activation of the Wnt/beta-catenin pathway in mouse embryonic stem cells treated with four GSK3 inhibitors. BMC Res Notes. 2014:7:273. doi:10.1186/1756-0500-7-273.

23. Naujok O, Diekmann U, Lenzen $\mathrm{S}$. The generation of definitive endoderm from human embryonic stem cells is initially independent from Activin A but requires canonical Wnt-signaling. Stem Cell Rev. 2014;10(4):480-93. doi:10.1007/s12015-014-9509-0.

24. Shelton M, Metz J, Liu J, Carpenedo Richard L, Demers S-P, Stanford William $L$, et al. Derivation and expansion of PAX7-positive muscle progenitors from human and mouse embryonic stem cells. Stem Cell Reports. 2014;3(3):51629. doi:10.1016/j.stemcr.2014.07.001.

25. Turner DA, Rue P, Mackenzie JP, Davies E, Arias A. Brachyury cooperates with Wnt/ss-Catenin signalling to elicit Primitive Streak like behaviour in differentiating mouse ES cells. BMC Biol. 2014;12(1):63. doi:10.1186/s12915-014-0063-7.

26. Pick M, Azzola L, Mossman A, Stanley EG, Elefanty AG. Differentiation of human embryonic stem cells in serum-free medium reveals distinct roles for bone morphogenetic protein 4, vascular endothelial growth factor, stem cell factor, and fibroblast growth factor 2 in hematopoiesis. Stem Cells. 2007;25(9):2206-14. doi:10.1634/stemcells.2006-0713.

27. Yurugi-Kobayashi T, Itoh H, Schroeder T, Nakano A, Narazaki G, Kita F, et al. Adrenomedullin/cyclic AMP pathway induces Notch activation and differentiation of arterial endothelial cells from vascular progenitors. Arterioscler Thromb Vasc Biol. 2006;26(9):1977-84. doi:10.1161/01.ATV.0000234978.10658.41.

28. Rufaihah AJ, Huang NF, Kim J, Herold J, Volz KS, Park TS, et al. Human induced pluripotent stem cell-derived endothelial cells exhibit functional heterogeneity. Am J Transl Res. 2013;5(1):21-35.

29. Lanner F, Sohl M, Farnebo F. Functional arterial and venous fate is determined by graded VEGF signaling and notch status during embryonic stem cell differentiation. Arterioscler Thromb Vasc Biol. 2007;27(3):487-93. doi:10.1161/01.ATV.0000255990.91805.6d.

30. Yamamizu K, Matsunaga T, Uosaki H, Fukushima H, Katayama S, Hiraoka-Kanie $\mathrm{M}$, et al. Convergence of Notch and beta-catenin signaling induces arterial fate in vascular progenitors. J Cell Biol. 2010;189(2):325-38. doi:10.1083/jcb.200904114.

31. Lawson ND, Vogel AM, Weinstein BM. sonic hedgehog and vascular endothelial growth factor act upstream of the Notch pathway during arterial endothelial differentiation. Dev Cell. 2002;3(1):127-36.

32. Lawson ND, Scheer N, Pham VN, Kim CH, Chitnis AB, Campos-Ortega JA, et al. Notch signaling is required for arterial-venous differentiation during embryonic vascular development. Development. 2001;128(19):3675-83.

33. Aranguren $X L$, Luttun A, Clavel C, Moreno C, Abizanda G, Barajas MA, et al. In vitro and in vivo arterial differentiation of human multipotent adult progenitor cells. Blood. 2007;109(6):2634-42. doi:10.1182/blood2006-06-030411.

34. Cooley LS, Edwards DR. New insights into the plasticity of the endothelial phenotype. Biochem Soc Trans. 2011;39(6):1639-43. doi:10.1042/BST20110723.

35. Moyon D, Pardanaud L, Yuan L, Breant C, Eichmann A. Plasticity of endothelial cells during arterial-venous differentiation in the avian embryo. Development. 2001;128(17):3359-70.

36. Nunes SS, Rekapally H, Chang CC, Hoying JB. Vessel arterial-venous plasticity in adult neovascularization. PLoS One. 2011;6(11):e27332. doi:10.1371/journal.pone.0027332.

37. Harvey NL, Oliver G. Choose your fate: artery, vein or lymphatic vessel? Curr Opin Genet Dev. 2004;14(5):499-505. doi:10.1016/j.gde.2004.07.005.

38. Oliver G, Srinivasan RS. Endothelial cell plasticity: how to become and remain a lymphatic endothelial cell. Development. 2010;137(3):363-72. doi:10.1242/dev.035360 
39. Nolan DJ, Ginsberg M, Israely E, Palikuqi B, Poulos MG, James D, et al. Molecular signatures of tissue-specific microvascular endothelial cell heterogeneity in organ maintenance and regeneration. Dev Cell. 2013;26(2):204-19. doi:10.1016/j.devcel.2013.06.017.

40. Sahara M, Hansson EM, Wernet O, Lui KO, Spater D, Chien KR. Manipulation of a VEGF-Notch signaling circuit drives formation of functional vascular endothelial progenitors from human pluripotent stem cells. Cell Res. 2014;24(7):820-41. doi:10.1038/cr.2014.59.

41. Orlova W, van den Hil FE, Petrus-Reurer S, Drabsch $Y$, Ten Dijke $P$, Mummery CL. Generation, expansion and functional analysis of endothelia cells and pericytes derived from human pluripotent stem cells. Nat Protoc. 2014;9(6):1514-31. doi:10.1038/nprot.2014.102.

42. Sturgeon CM, Ditadi A, Awong G, Kennedy M, Keller G. Wnt signaling controls the specification of definitive and primitive hematopoiesis from human pluripotent stem cells. Nat Biotechnol. 2014;32(6):554-61. doi:10.1038/nbt.2915.

43. Borchin B, Chen J, Barberi T. Derivation and FACS-mediated purification of PAX3+/PAX7+ skeletal muscle precursors from human pluripotent stem cells. Stem Cell Rep. 2013;1(6):620-31. doi:10.1016/j.stemcr.2013.10.007.

44. Cao N, Liang H, Huang J, Wang J, Chen Y, Chen Z, et al. Highly efficient induction and long-term maintenance of multipotent cardiovascular progenitors from human pluripotent stem cells under defined conditions. Cell Res. 2013;23(9):1119-32. doi:10.1038/cr.2013.102.

45. Lian X, Hsiao C, Wilson G, Zhu K, Hazeltine LB, Azarin SM, et al. Robust cardiomyocyte differentiation from human pluripotent stem cells via temporal modulation of canonical Wnt signaling. Proc Natl Acad Sci U S A. 2012;109(27):E1848-57. doi:10.1073/pnas.1200250109.

46. Bai H, Gao Y, Arzigian M, Wojchowski DM, Wu WS, Wang ZZ. BMP4 regulates vascular progenitor development in human embryonic stem cells through a Smad-dependent pathway. J Cell Biochem. 2010;109(2):363-74.

47. Song SH, Jung W, Kim KL, Hong W, Kim HO, Lee KA, et al. Distinct transcriptional profiles of angioblasts derived from human embryonic stem cells. Exp Cell Res. 2013;319(8):1136-45. doi:10.1016/j.yexcr.2013.02.019.

48. Narazaki G, Uosaki H, Teranishi M, Okita K, Kim B, Matsuoka S, et al. Directed and systematic differentiation of cardiovascular cells from mouse induced pluripotent stem cells. Circulation. 2008;118(5):498-506. doi:10.1161/CIRCULATIONAHA.108.769562.

49. Boyer-Di Ponio J, El-Ayoubi F, Glacial F, Ganeshamoorthy K, Driancourt C, Godet $M$, et al. Instruction of circulating endothelial progenitors in vitro towards specialized blood-brain barrier and arterial phenotypes. PLoS One. 2014;9(1):e84179. doi:10.1371/journal.pone.0084179.

50. Lippmann ES, Al-Ahmad A, Azarin SM, Palecek SP, Shusta EV. A retinoic acid-enhanced, multicellular human blood-brain barrier model derived from stem cell sources. Sci Rep. 2014:4:4160. doi:10.1038/srep04160.

51. Lippmann ES, Azarin SM, Kay JE, Nessler RA, Wilson HK, Al-Ahmad A, et al. Derivation of blood-brain barrier endothelial cells from human pluripotent stem cells. Nat Biotechnol. 2012;30(8):783-91. doi:10.1038/nbt.2247.

52. Kurian L, Sancho-Martinez I, Nivet E, Aguirre A, Moon K, Pendaries C, et al. Conversion of human fibroblasts to angioblast-like progenitor cells. Nat Methods. 2013;10(1):77-83. doi:10.1038/nmeth.2255.

53. Samuel R, Daheron L, Liao S, Vardam T, Kamoun WS, Batista A, et al. Generation of functionally competent and durable engineered blood vessels from human induced pluripotent stem cells. Proc Natl Acad Sci U S A. 2013;110(31):12774-9. doi:10.1073/pnas.1310675110.

54. Lei T, Jacob S, Ajil-Zaraa I, Dubuisson JB, Irion O, Jaconi M, et al. Xeno-free derivation and culture of human embryonic stem cells: current status, problems and challenges. Cell Res. 2007;17(8):682-8. doi:10.1038/cr.2007.61.

55. Rodin S, Antonsson L, Niaudet C, Simonson OE, Salmela E, Hansson $E M$, et al. Clonal culturing of human embryonic stem cells on laminin-521/E-cadherin matrix in defined and xeno-free environment. Nat Commun. 2014;5:3195. doi:10.1038/ncomms4195.

56. Wang Y, Chou BK, Dowey S, He C, Gerecht S, Cheng L. Scalable expansion of human induced pluripotent stem cells in the defined xeno-free E8 medium under adherent and suspension culture conditions. Stem Cell Res. 2013;11(3):1103-16. doi:10.1016/j.scr.2013.07.011.

57. Sampsell-Barron T. Xeno-free adaptation and culture of human pluripotent stem cells. Methods Mol Biol. 2013;1001:81-97. doi:10.1007/978-1-62703-363-3_8.

58. Bergstrom R, Strom S, Holm F, Feki A, Hovatta O. Xeno-free culture of human pluripotent stem cells. Methods Mol Biol. 2011;767:125-36. doi:10.1007/978-1-61779-201-4_9.
59. Rajala K, Lindroos B, Hussein SM, Lappalainen RS, Pekkanen-Mattila M, Inzunza J, et al. A defined and xeno-free culture method enabling the establishment of clinical-grade human embryonic, induced pluripotent and adipose stem cells. PLoS One. 2010;5(4):e10246. doi:10.1371/journal.pone. 0010246.

\section{Submit your next manuscript to BioMed Central and take full advantage of:}

- Convenient online submission

- Thorough peer review

- No space constraints or color figure charges

- Immediate publication on acceptance

- Inclusion in PubMed, CAS, Scopus and Google Scholar

- Research which is freely available for redistribution

Submit your manuscript at www.biomedcentral.com/submit 